\title{
Harmonização de Normas para o Transporte Rodoviário Internacional de Cargas entre Países da América do Sul
}

\section{Harmonization of Rules for the International Road Freight Transportation between South American Countries}

\author{
Hugo Alves Silva Ribeiro \\ Agência Nacional de Transportes Terrestres (ANTT) \\ E-mail: hugoalves.ribeiro@yahoo.com.br \\ Nathane Eva Santos Peixoto \\ Instituto Federal de Brasília (IFB) \\ E-mail: nathaneeva@hotmail.com \\ Kleber Carlos Ribeiro Pinto \\ Universidade Federal de Uberlândia (UFU) \\ E-mail: kleber@ufu.br
}

\begin{abstract}
Resumo: As negociações internacionais que envolvem aspectos técnicos e políticos normalmente são pautadas em interesses específicos de cada nação. No caso do transporte rodoviário internacional de cargas (TRIC) não é diferente. Alguns países impedem o ingresso em seu território de veículos de carga com pesos e dimensões um pouco acima do padrão tradicional, especialmente devido às estratégias mercadológicas ou às limitações de infraestrutura. Esses fatos podem prejudicar a logística internacional que afeta tanto o Brasil quanto os demais países signatários de acordos de transporte terrestre, uma vez que o avanço tecnológico faz com que haja veículos cada vez maiores. Este artigo tem a finalidade de propor a harmonização de regras do TRIC nessas nações sul-americanas, a partir da análise dos normativos de cada Estado Parte. Para isso, foi utilizada uma ferramenta de gestão dos registros das atas de reuniões bilaterais e multilaterais para análise sistemática dos acordos dos países. Como método, o trabalho alia a teoria do direito comparado e integração regional na busca por subsidiar futuras pesquisas e negociações internacionais.
\end{abstract}

Palavras-Chave: acordos internacionais; transporte rodoviário internacional de cargas; pesos e dimensões; integração regional.

Abstract: International negotiations involving technical and political aspects are usually based on the specific interests of each nation. In the case of international road freight transportation (IRFT) it is no different. Some countries prevent entry into their territory of weight vehicles 
RIBEIRO, Hugo Alves Silva; PEIXOTO, Nathane Eva Santos; PINTO, Kleber Carlos Ribeiro. Harmonização de Normas para o Transporte Rodoviário Internacional de Cargas entre Países da América do Sul.

with weights and dimensions slightly above the traditional standard, especially due to market strategies or infrastructure limitations. These facts can undermine the international logistics that affect both Brazil and other countries that are signatories to land transportation agreements, since the technological advance makes vehicles bigger and bigger. This paper proposes the harmonization of IRFT rules in these South American nations, based on the analysis of the regulations of each State Party. For this purpose, a tool was used to manage the records of bilateral and multilateral meetings, in order to systematically analyze the agreement between the countries. As a method, the scientific work combines the theory of comparative law and regional integration to support future international research and negotiations.

Keywords: international agreements; international road freight transportation; weights and dimensions; regional integration.

\section{Introdução}

Estima-se que o Transporte Rodoviário Internacional de Cargas (TRIC) movimentou no ano de 2018 aproximadamente US\$14,5 bilhões (Free On Board - FOB ${ }^{1}$ ), o que corresponde a aproximadamente $70 \%$ da carga exportada do Brasil para o Mercosul e $40 \%$ do Brasil para a América do Sul (Comex Stat, 2018). Esses dados ressaltam a relevância das tratativas que envolvem o TRIC para os interesses comerciais das nações.

No entanto, para efetiva transação comercial, foram firmados diversos acordos entre os países interessados, não apenas no viés mercantil, mas também no âmbito de regulação do transporte internacional. Isso porque um pacto econômico poderia não ser operacionalizado sem a devida harmonização normativa entre os países. Por exemplo, antes de 1990, as ausências de acordos internacionais específicos sobre transportes terrestres resultavam, em alguns casos, em restrição da movimentação de carga entre as nações.

Cada país, dependendo de sua cultura, estratégia econômico-social e infraestrutura rodoviária, estabelece normas de trânsito de veículos de carga que melhor se adequem às suas necessidades. Dessas normas destacam-se duas: (i) a capacidade de carga máxima permitida por eixo do veículo - aqui tratado como "peso"; (ii) dimensões máximas dos veículos que podem transitar pelas vias sem a necessidade de autorizações especiais.

\footnotetext{
${ }^{1}$ Trata-se do montante movimentado na modalidade de compartilhamento de responsabilidades entre comprador e vendedor. Na modalidade FOB, o comprador assume os riscos e custos com o transporte após o carregamento, enquanto que o fornecedor se responsabiliza até que a mercadoria seja colocada dentro do veículo.
}

Revista Brasileira de Políticas Públicas e Internacionais, v.4, n.1, julho/2019, pp. 131-151. 
RIBEIRO, Hugo Alves Silva; PEIXOTO, Nathane Eva Santos; PINTO, Kleber Carlos Ribeiro. Harmonização de Normas para o Transporte Rodoviário Internacional de Cargas entre Países da América do Sul.

Devido às diferenças das regras existentes entre os países limítrofes ao Brasil e a necessidade de trânsito mútuo de veículos de cargas entre os Estados Parte, é essencial buscar a harmonização de seus normativos internos a fim de que haja manutenção da ordem e inibição de conflitos. Para tanto, diversos acordos foram realizados durante as últimas décadas acerca especificamente dessa temática. Esses acordos foram pactuados em reuniões das delegações que representam cada país e, atualmente, alguns estão internalizados como normas, resoluções ou decretos, enquanto outros estão contidos apenas nas atas das reuniões.

Com o objetivo de propor uma harmonização normativa sobre o assunto visando a integração regional, este artigo analisa, por meio da técnica do direito comparado, os documentos referentes às ações pactuadas acerca de pesos e dimensões no transporte rodoviário internacional de cargas. Para isso, utiliza a revisão sistemática meta analítica dos acordos dos países, realizada mediante uma ferramenta de gestão governamental, mantida pela Agência Nacional de Transportes Terrestres (ANTT), intitulada Sistema Transporte Rodoviário Internacional - TRI (ANTT, 2018). Trata-se de um repositório de documentos, de livre acesso, que contém a consolidação e estruturação das atas de reuniões bilaterais e multilaterais realizadas entre o Brasil e demais Estados Parte.

\section{Transporte Rodoviário Internacional de Cargas}

O transporte de cargas é um importante impulsionador econômico, tanto brasileiro quanto da América do Sul. Por essa razão, no ano 2000, formou-se a Iniciativa para Integração de Infraestrutura Regional Sul-Americana (IIRSA) e, em sua decorrência, foram criados Eixos de Integração e Desenvolvimento, dos quais destaca-se o Eixo Interoceânico Central (EIC) como um dos prioritários à integração regional (Jaeger, 2017).

De forma exemplificativa, apenas entre o Brasil e o Peru no âmbito rodoviário citam-se as seguintes ações de aproximação entre países (Ribeiro, 2017): (i) construção da ponte sobre o Rio Madeira em Abunã-RO (BR-364); (ii) a assinatura do Acordo de Ampliação EconômicoComercial, firmado no final de 2016, que prevê a liberalização de serviços bem como a criação de novos acordos comerciais; (iii) a perspectiva de operação da "Rota Transoceância" para o escoamento da soja, a qual se apresenta como opção aceitável em caso de eventual pane

Revista Brasileira de Políticas Públicas e Internacionais, v.4, n.1, julho/2019, pp. 131-151. 
RIBEIRO, Hugo Alves Silva; PEIXOTO, Nathane Eva Santos; PINTO, Kleber Carlos Ribeiro. Harmonização de Normas para o Transporte Rodoviário Internacional de Cargas entre Países da América do Sul.

logística dos portos brasileiros para exportação para a China. Da mesma forma, ações semelhantes existem para cada país sul-americano, e grande parte delas originam e demandam serviços de TRIC.

Em termos quantitativos, o TRIC também é fortemente presente no país. Segundo dados da ANTT, em 31 de maio de 2019 havia 1.534 empresas nacionais e 1.860 empresas estrangeiras habilitadas para prestar serviços de TRIC, das quais mantinham quase 110 mil veículos registrados para essa finalidade. Segundo dados da Associação Brasileira de Transportadores Internacionais (ABTI), no ano de 2016 quase 550 mil caminhões cruzaram apenas as fronteiras do Brasil com o Uruguai, Paraguai, Argentina e Bolívia (ABTI, 2016).

No contexto brasileiro, a chamada Faixa de Fronteira (FF) é uma região importante para essa movimentação de mercadorias, a qual equivale à região entre os limites geográficos do país e a sua distância em linha reta de $150 \mathrm{~km}$, representando $34 \%$ do território nacional (Santos, 2017). Nessa FF estão contempladas as cidades limítrofes, que normalmente possuem Comitês de Fronteira que visam o fortalecimento e a integração regional, algumas delas muito dependentes do TRIC. Ainda tomando como exemplo o Peru, um fato interessante ocorreu em 2014 durante a cheia do Rio Madeira, que isolou o Acre do restante do país, fazendo-o ser essencialmente abastecido por mercadorias peruanas transportadas por meio rodoviário.

De acordo com Huertas (2013), que estudou o transporte rodoviário de mercadorias no Brasil, o epicentro desse modo de transporte no país é o Estado de São Paulo, mas "a força desse conjunto também reside nos acessos rodoviários ao Mercosul" (Huertas, 2013, p. 250). O autor destaca os eixos rodoviários e suas importâncias no contexto econômico e geográfico da nação.

Na busca por essa integração entre os países da América do Sul, existem 258 projetos para melhoria da infraestrutura rodoviária de ligação internacional a serem concluídos até 2022, com investimento previsto de US\$ 69.354,20 milhões (COSIPLAN, 2017). Mas, para que seja possível operar de modo integrado e com mais eficiência nesse ambiente, é fundamental a harmonização normativa entre Governos desses Estados Parte especialmente, no que tange ao TRIC. Pesquisa da Confederação Nacional das Indústrias (CNI) confirma que, dentre outras, são causas para a baixa integração logística na América do Sul tanto os acordos conflitantes

Revista Brasileira de Políticas Públicas e Internacionais, v.4, n.1, julho/2019, pp. 131-151. 
RIBEIRO, Hugo Alves Silva; PEIXOTO, Nathane Eva Santos; PINTO, Kleber Carlos Ribeiro. Harmonização de Normas para o Transporte Rodoviário Internacional de Cargas entre Países da América do Sul.

entre as esferas binacionais, sub-regionais e regionais realmente, quanto as diferentes prioridades de cada nação (CNI, 2015).

\section{Referencial teórico-metodológico}

$\mathrm{Na}$ busca pela harmonização normativa dos pesos e dimensões dos veículos de transporte rodoviário internacional de cargas entre os países participantes do Acordo sobre Transporte Internacional Terrestre (ATIT) ou do Mercosul, este artigo se fundamenta em três vertentes teórico-metodológicas. A primeira se sustenta na integração regional, a segunda nas negociações internacionais, e a última no direito comparado. Para seleção dos normativos que tratam sobre a temática, este trabalho utilizou a técnica de revisão sistemática com enfoque meta analítico por meio do sistema TRI.

\subsection{Integração Regional}

Para Pecequilo (2015) existem dois tipos de atores: estatais e não estatais. Segundo Granato \& Batista (2018), enquanto as políticas públicas tradicionais têm por contraparte um cidadão, a integração regional possui como contraparte um outro Estado, soberano e com interesses próprios. Trata-se de uma técnica cotidianamente utilizada no âmbito de negociações internacionais, que tenta convencer outros países acerca dos benefícios de uma harmonização normativa. A consequência desse processo de integração costuma gerar a transferência de parte de sua soberania para uma entidade política ou para determinada instituição (Granato \& Batista, 2018; Juárez \& Conde, 2015).

No âmbito da teoria funcionalista, a melhor forma de integração é a cooperação de certas tarefas funcionais entre os Estados Parte, considerando aspectos de longo prazo (dinâmicos) com menor interferência partidária (Pinto, 2004). Acerca disso Pinto (2004) recomenda que sejam feitos acordos sem a criação de novas estruturas institucionais no plano político, aproveitando efeitos de economias de escala e vantagens de especialização. Trata-se da aplicação prática da teoria funcionalista, concebida por Mitrany (1933). Nesse contexto, a ANTT pode ser considerada uma autarquia estratégica para o Brasil, ou seja, a instituição já

Revista Brasileira de Políticas Públicas e Internacionais, v.4, n.1, julho/2019, pp. 131-151. 
RIBEIRO, Hugo Alves Silva; PEIXOTO, Nathane Eva Santos; PINTO, Kleber Carlos Ribeiro. Harmonização de Normas para o Transporte Rodoviário Internacional de Cargas entre Países da América do Sul.

consolidada que possui ferramentas e meios capazes de promover essa harmonização normativa do TRIC.

\subsection{Negociações Internacionais}

Para Gonçalves (2016), o Estado não atua unilateralmente, sendo sua conduta uma reflexão de disputas dentro de grupos de interesse. Portanto, as negociações internacionais exigem dos profissionais que atuam nessa área o conhecimento de diretrizes práticas a fim de conseguirem o melhor negócio possível com pessoas e organizações (Acuff, 2004).

No âmbito teórico, as negociações aqui almejadas podem ser análogas ao modelo dos Jogos de Dois Níveis (JDN), de Putnam (1993). Acerca disso, o autor considera que toda negociação internacional envolve dimensão doméstica, a qual estabelece limites para o negociador do país atuar no processo de convencimento com outras nações. Para isso é essencial que o negociador desenvolva uma situação cooperativa de modo que viabilize o acordo e, conforme o caso, barganhar os interesses de sua nação (Veiga, 2002).

\subsection{Direito Comparado}

Diante do exposto, tendo em foco o objetivo de harmonização normativa, é necessário analisar o arcabouço legal de cada Estado Parte que integrará a negociação, de modo a compará-los e consolidá-los em um entendimento único comum. De acordo com Maia \& Jacintho (2018), essa técnica pode ser conhecida por direito comparado. Para os autores, esse estudo reduz os riscos da atividade normativa, pois amplia a visão do legislador por meio do conhecimento e das soluções práticas aplicadas em outros países. Tal técnica é interessante a fim de fundamentar posicionamento de um Estado Parte nessas negociações internacionais.

Para Cardoso (2010), o direito comparado também é útil nas investigações históricas, para aperfeiçoar o direito nacional e ainda para compreender os povos estrangeiros de modo a melhor estabelecer relações da vida internacional. Trata-se de uma técnica comumente aplicada quando se trata de aspectos relacionados à harmonização de regras entre culturas distintas (Nascimento \& Muniz, 2012).

Revista Brasileira de Políticas Públicas e Internacionais, v.4, n.1, julho/2019, pp. 131-151. 
RIBEIRO, Hugo Alves Silva; PEIXOTO, Nathane Eva Santos; PINTO, Kleber Carlos Ribeiro. Harmonização de Normas para o Transporte Rodoviário Internacional de Cargas entre Países da América do Sul.

\subsection{Revisão Sistemática de Normativos: Sistema TRI}

Nada adianta comparar normativos se não houver um meio sistemático para realizar as buscas na legislação vigente. Para isso procedeu-se com pesquisa à base de dados do Sistema TRI (ANTT, 2018), com enfoque sistemático e meta analítico. Essa abordagem de pesquisa se assemelha à técnica conhecida por Teoria do Enfoque Meta Analítico (TEMAC), apresentada por Mariano \& Rocha (2017), mas neste aspecto se restringe a uma única base consolidadora de informações, ou seja, o sistema TRI publicamente acessível e disponível pela ANTT (2018). A busca sistematizada foi realizada em 15 de fevereiro de 2017, por meio das seguintes etapas:

- Etapa 1: Consulta ao sistema por meio da palavra "dimensão" (sem aspas). Resultado: 170 documentos.

- Etapa 2: Filtragem por assunto "Pesos e Dimensões". Resultado: 81 documentos.

- Etapa 3: Filtragem por data, da mais antiga para a mais recente. Resultados:

- Antes de 1992: 14 documentos.

○ 1992 - 1997: 8 documentos.

○ 1998 - 2002: 4 documentos.

○ 2003 - 2007: 21 documentos.

○ 2008-2012: 14 documentos.

○ 2013 - 2016: 18 documentos.

○ 2017 ou mais recente: 2 documentos.

- Etapa 4: Procedeu-se a análise de todos os documentos, um a um. Resultado: 81 documentos.

- Etapa 5: Foram descartados 17 documentos da análise, os quais não contribuiriam para o objetivo do trabalho. Resultado: 64 documentos.

- Etapa 6: Tabulação e comparação dos resultados. Resultado: 64 documentos.

\section{Contextualização Histórica: Mercosul e ATIT}

Um dos acordos que traz os primórdios da regulamentação do TRIC é o Tratado de Montevidéu 1980, que foi aprovado e internalizado no Brasil mediante publicação do Decreto Revista Brasileira de Políticas Públicas e Internacionais, v.4, n.1, julho/2019, pp. 131-151. 
RIBEIRO, Hugo Alves Silva; PEIXOTO, Nathane Eva Santos; PINTO, Kleber Carlos Ribeiro. Harmonização de Normas para o Transporte Rodoviário Internacional de Cargas entre Países da América do Sul.

$n^{\circ}$ 87.054, em 1982. Desde então, o seu art. 14 permite que os países membros estabeleçam normas específicas de outras modalidades de acordos, das quais incluem a regulamentação de dimensões e pesos máximos de veículos de carga que transitarem entre os Estados Partes.

Em 1990, foi promulgado pelo governo brasileiro o Decreto $\mathrm{n}^{\circ} 99.704$, que dispõe sobre a execução do Acordo sobre Transporte Internacional Terrestre (ATIT) entre o Brasil, Argentina, Bolívia, Chile, Paraguai, Peru e Uruguai. No que tange às habilitações de veículos de carga para trânsito entre os países, destaca-se o art. 31, que aceita eventuais acordos bilaterais diferentes daqueles originalmente estabelecidos multilateralmente.

Portanto, o acordo geral para o trânsito de determinado veículo entre os Estados Partes que executam o ATIT é que o transportador deverá observar as normas de dimensões e pesos máximos do país em que ocorre a movimentação da carga. Essa situação acaba por gerar possíveis conflitos normativos e operacionais, o que prejudica a eficiência logística. Ademais, tal fato pode eventualmente causar concorrência desleal entre transportadoras de países distintos, uma vez que a capacidade do veículo influencia no preço unitário de alguns fretes. Entretanto, nada impede que haja acordos específicos entre as nações, os quais comumente ocorrem e serão abordados posteriormente neste trabalho.

Vale destacar que os membros plenos do Mercosul são Brasil, Paraguai, Uruguai e Argentina. Já os países que integram o ATIT quanto ao transporte rodoviário de carga são, além dos membros plenos do Mercosul, Peru, Bolívia e Chile. Ademais, a Venezuela e a Guiana Francesa possuem acordos bilaterais específicos com o Brasil sobre algumas temáticas (Figura 1).

Revista Brasileira de Políticas Públicas e Internacionais, v.4, n.1, julho/2019, pp. 131-151. 
RIBEIRO, Hugo Alves Silva; PEIXOTO, Nathane Eva Santos; PINTO, Kleber Carlos Ribeiro. Harmonização de Normas para o Transporte Rodoviário Internacional de Cargas entre Países da América do Sul.

Figura 1: Países que integram o ATIT e o Mercosul (membros plenos)

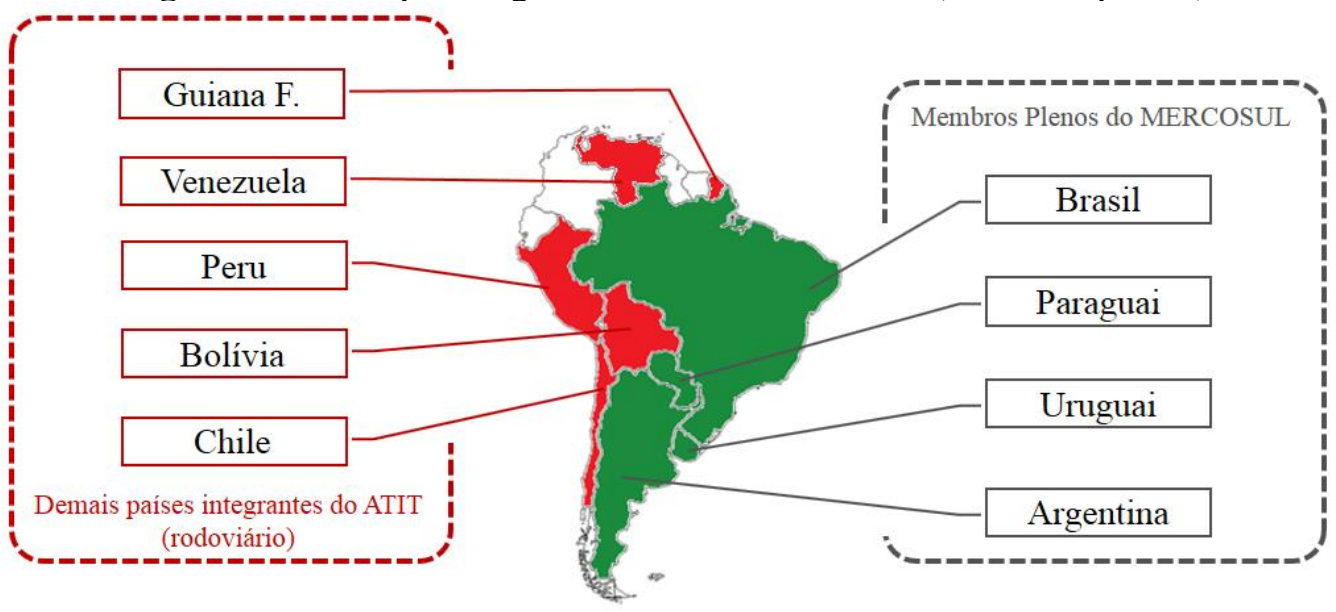

Fonte: Elaborado pelos autores.

\section{Pesos e Dimensões no Mercosul}

Nas II e III Reuniões do Subgrupo do Mercado Comum Brasil/Argentina, realizadas em Foz do Iguaçu entre novembro e dezembro de 1990, iniciaram-se as tratativas mais importantes para concretizar os "Acordos sobre Pesos e Dimensões". Esse acordo só foi aprovado na II Reunião Quatripartite do Subgrupo de Trabalho $\mathrm{n}^{\mathrm{o}} 5$ - Transporte Terrestre do Mercosul, realizada em Assunção em 19 e 20 de junho de 1991, intitulado "Acordo sobre Pesos e Dimensões de Veículos". Porém, esse pacto não chegou a ser incorporado ao acervo normativo do Mercosul.

Com isso, desde então, diversas reuniões bilaterais e multilaterais voltaram a discutir a pauta de pesos e dimensões, tanto pelo descumprimento de alguns Estados Partes daquilo que fora estabelecido nas reuniões, quanto pela necessidade de revisão da matéria. O consenso só ocorreu em 2008, com a publicação da Resolução no 65/08 do Grupo Mercado Comum (GMC), intitulado de "Acordo Sobre Pesos e Dimensões para Veículos de Transporte Rodoviário de Passageiros e Cargas”. Esse ato foi assinado pelos representantes do Brasil, Argentina, Paraguai e Uruguai. A internalização desse conteúdo ocorreu, no Brasil, por meio do Decreto $\mathrm{n}^{\circ}$ 7.282 em 2010, mas desde 2009 já estava sendo aplicado mediante Resolução no 318 do Conselho Nacional de Trânsito (Contran).

Revista Brasileira de Políticas Públicas e Internacionais, v.4, n.1, julho/2019, pp. 131-151. 
RIBEIRO, Hugo Alves Silva; PEIXOTO, Nathane Eva Santos; PINTO, Kleber Carlos Ribeiro. Harmonização de Normas para o Transporte Rodoviário Internacional de Cargas entre Países da América do Sul.

No que tange aos pesos, esses últimos normativos estabelecem os limites máximos para cada eixo, dependendo do número de rodas disponíveis. Existem eixos com duas rodas ou quatro rodas, e eixos "simples", "duplo" ou "triplo". A Figura 2 ilustra essa diferenciação.

Figura 2: Diferenciação entre tipos de eixos e número de rodas por eixo

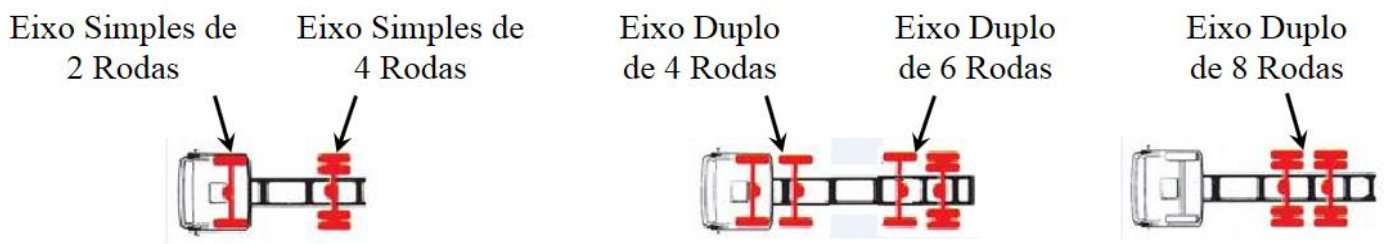

Fonte: Elaborado pelos autores.

Ainda houve regulamentação do Peso Bruto Total (PBT) máximo de uma composição, que não deve exceder 45 toneladas (ton). Quanto a isso, é válido lembrar que o PBT contempla o somatório da tara do veículo com a lotação total imposta (Figura 3).

Figura 3: Representação do Peso Bruto Total (PBT) de um veículo.

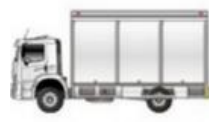

Tara

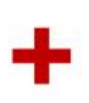

Lotação

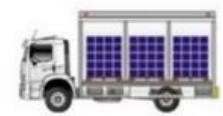

PBT

Fonte: Adaptado de Frete Com Lucro (2019).

Feitas essas considerações, para cada composição de eixos e rodas, a Resolução GMC $n^{\circ}$ 65/08, internalizada pelo Decreto no 7.862/10, define o limite máximo de carga. Esse limite está apresentado na Tabela 1.

Tabela 1: Limite de carga por eixo, conforme o número de rodas por eixo

\begin{tabular}{rrr} 
Eixos & Quantidade de Rodas & Limite (ton) \\
\hline Simples & 2 & 6 \\
Simples & 4 & 10,5 \\
\hline Duplo & 4 & 10 \\
Duplo & 6 & 14 \\
Duplo & 8 & 18 \\
\hline Triplo & 6 & 14 \\
Triplo & 10 & 21 \\
Triplo & 12 & 25,5 \\
\hline & Fonte: Resolução GMC $\mathrm{n}^{\mathbf{0}}$ 65/08
\end{tabular}

Revista Brasileira de Políticas Públicas e Internacionais, v.4, n.1, julho/2019, pp. 131-151. 
RIBEIRO, Hugo Alves Silva; PEIXOTO, Nathane Eva Santos; PINTO, Kleber Carlos Ribeiro. Harmonização de Normas para o Transporte Rodoviário Internacional de Cargas entre Países da América do Sul.

Quanto às dimensões, o referido normativo define que, para ser considerado eixo "duplo" ou "triplo", a distância entre os centros das rodas deve estar entre 1,20 m e 2,40 m. Ademais, há limitação de largura máxima em 2,6 m e de altura máxima de 4,3 m. A Figura 4 representa essas dimensões.

Figura 4: Representação esquemática dos comprimentos máximos definidos pelo Mercosul
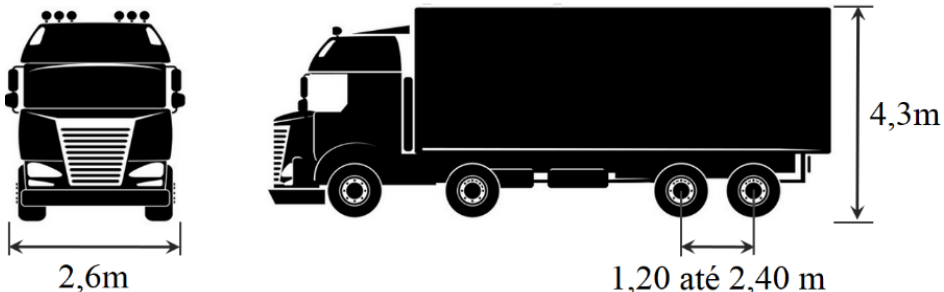

Fonte: Elaborado pelos autores, com informações da Resolução GMC nº 65/08

O comprimento máximo do veículo varia conforme a sua característica. Caminhão simples não deve ultrapassar $14 \mathrm{~m}$, enquanto que um caminhão trator com semirreboque tem seu comprimento limitado a 18,6 m. A Figura 5 apresenta esquematicamente essas distâncias.

Figura 3: Comprimento máximo dos veículos conforme estabelece o Mercosul

\begin{tabular}{|c|c|}
\hline & Comprimento Máximo (m) \\
\hline Caminhão Simples & 14 \\
\hline Caminhão com Reboque & 20 \\
\hline Reboque & 8,6 \\
\hline $\begin{array}{l}\text { Caminhão Trator com } \\
\text { Semirreboque }\end{array}$ & 18,6 \\
\hline $\begin{array}{c}\text { Caminhão Trator com } \\
\text { Semirreboque e } \\
\text { Reboque }\end{array}$ & 20,5 \\
\hline
\end{tabular}

Fonte: Adaptado de Frete Com Lucro (2019), com informações da Resolução GMC nº 65/08

Porém, esse regramento não traz a forma em que a medição da carga deve ser realizada, devido aos diversos tipos de instrumentos (balanças) disponíveis ao longo das rodovias dos Revista Brasileira de Políticas Públicas e Internacionais, v.4, n.1, julho/2019, pp. 131-151. 
RIBEIRO, Hugo Alves Silva; PEIXOTO, Nathane Eva Santos; PINTO, Kleber Carlos Ribeiro. Harmonização de Normas para o Transporte Rodoviário Internacional de Cargas entre Países da América do Sul.

Estados Partes. Isso impossibilitou o estabelecimento de tolerâncias admitidas, fazendo com que o normativo, embora bem estruturado, careça de normas essenciais para a fiscalização. A discussão sobre essas tolerâncias está constantemente presente nas pautas das reuniões do Subgrupo de Trabalho no 5 - "Transportes”, do Mercosul.

Conforme já apresentado, ainda que haja um consenso aparente acerca de "pesos e dimensões" entre os países do Mercosul, nada impede que acordos bilaterais se sobressaiam entre as nações. Na verdade, isso é bastante comum devido às características regionais de transporte. No caso do Brasil e dos demais países limítrofes, por exemplo, muitos desses acordos foram definidos em reunião bilateral, e apenas constam nas atas assinadas entre os participantes. Infelizmente, diversos deles sequer foram oficialmente internalizados em seus regulamentos nacionais, mas encontram-se vigentes devido à existência da referida ata. Por essa razão, e devido à dificuldade de consolidação de tantos normativos em um único documento, busca-se identificá-los e consolidá-los em uma proposta harmônica entre os países.

\section{Resultado da Análise dos Acordos Bilaterais.}

\subsection{Paraguai}

Em 2010, durante a Reunião Extraordinária Brasil/Paraguai dos organismos de aplicação do ATIT, a delegação paraguaia informou que em seu país foi aprovado o PBT máximo de 49,5 toneladas para caminhões tratores com reboques. Esse fato ocorreu mediante a Resolução do Ministério de Obras Públicas e Comunicação (MOPC) de nº 2.043/2010. Sendo assim, solicitou que a delegação brasileira cedesse a permissão para que esse tipo de composição pudesse trafegar em vias do Brasil.

Diante dessa solicitação, em 2011 durante a XXXII Reunião Bilateral Brasil/Paraguai dos Organismos de Aplicação do ATIT, a delegação brasileira concordou em aumentar o PBT do caminhão trator com semirreboque para um meio-termo entre o existente e o apresentado pela delegação paraguaia. Ficou definido que entre os países haveria incremento do PBT máximo de 45 ton para 48,5 ton.

Revista Brasileira de Políticas Públicas e Internacionais, v.4, n.1, julho/2019, pp. 131-151. 
RIBEIRO, Hugo Alves Silva; PEIXOTO, Nathane Eva Santos; PINTO, Kleber Carlos Ribeiro. Harmonização de Normas para o Transporte Rodoviário Internacional de Cargas entre Países da América do Sul.

\subsection{Uruguai}

A preocupação da delegação uruguaia normalmente se versou sobre a infraestrutura de suas vias, especialmente no que tange à capacidade de carga sobre pontes e viadutos, e à altura máxima dos veículos devido aos eventuais obstáculos existentes. Nesse sentido, foi apresentado à delegação brasileira em 2008 um mapa contendo as rotas permitidas para o trânsito de composições de até 25,5 ton em eixos triplos de 12 rodas e altura máxima de 4,3m. Esse mapa e demais aspectos específicos estão detalhadamente apresentados no artigo de Rotondo (2018).

Em 2011 a delegação uruguaia tentou inserir nas discussões do Mercosul a possibilidade de utilização de pneus extralargos (pneumáticos mais largos que o convencional - Figura 6), com aumento na capacidade máxima de carga de 6 ton para 7 ton. Trata-se de uma tecnologia de pneus cada vez mais presente no mercado interno de cada país (já adotada no Brasil, Uruguai, Argentina, Venezuela e Chile), tanto por substituir a rodagem dupla quanto pelas vantagens econômicas em algumas situações (Lema, 2013). No entanto, esse assunto não está pacificado no âmbito internacional entre os Estados Parte. O tema sobre harmonização do uso desses pneus foi retirado da pauta daquelas reuniões desde 2014, e não houve relatos de novas tratativas que envolvem o Brasil.

Figura 4: Comparação entre rodagem dupla com pneus normais (esquerda) e rodagem com pneus extralargos (direita)

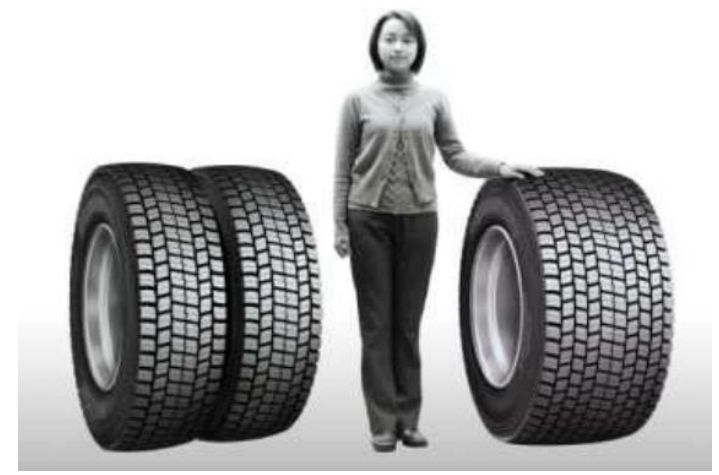

Fonte: Lema (2013).

Desde 2011, com a internalização da Resolução GMC nº 65/08 pelo Uruguai, a altura máxima de 4,3 m passou a ser atendida na maioria das rotas internacionais. Em 2012, na XX Reunião Bilateral Uruguai - Brasil, a delegação uruguaia apresentou nova rota que permitiria o Revista Brasileira de Políticas Públicas e Internacionais, v.4, n.1, julho/2019, pp. 131-151. 
RIBEIRO, Hugo Alves Silva; PEIXOTO, Nathane Eva Santos; PINTO, Kleber Carlos Ribeiro. Harmonização de Normas para o Transporte Rodoviário Internacional de Cargas entre Países da América do Sul.

tráfego de veículos com 25,5t de carga, mas relembrou que não há consenso acerca das tolerâncias de medição em balanças. Durante a Reunião Multilateral de aplicação do ATIT entre Uruguai, Argentina e Brasil, ocorrida em 2013, acordou-se que esses Estados aplicariam a totalidade da Resolução GMC nº 65/08 a partir de $1^{\circ}$ de julho de 2013.

\subsection{Bolívia}

Em 1993, em reunião bilateral entre Brasil e Bolívia, as delegações acordaram que cada veículo de carga deveria respeitar as normas vigentes no país de trânsito, conforme definido no Acordo do Cone Sul. Isso prosperou até as discussões sobre pesos e dimensões no Mercosul, finalizadas em 2008.

Posteriormente, em 2013 durante a XIII Reunião Bilateral com o Brasil, o governo boliviano assumiu a preocupação desses acordos no que tange à sua infraestrutura nacional. Segundo a delegação boliviana, suas estradas estavam sendo reformadas para adequar às regras do Mercosul mas, de modo geral, só seriam permitidos veículos de até 4,1 m de altura, e carga máxima de 45 ton para veículos com 6 eixos e 42 ton para veículos de 5 eixos. Excepcionalmente para o Brasil, a Bolívia permitiria a altura máxima de 4,3 $\mathrm{m}$ em algumas rotas, que seriam apresentadas em momento posterior. Não há relatos de atualizações sobre essa temática.

\subsection{Venezuela}

Desde 1997, na Segunda Reunião Bilateral dos organismos nacionais, Brasil e Venezuela vêm estabelecendo negociações acerca de pesos e dimensões de veículos rodoviários de carga. Naquela época, como não havia consenso, ficou estabelecido que cada veículo deveria respeitar as normas do país de trânsito.

Em 2005, durante a VI Reunião Bilateral Brasil e Venezuela dos organismos de aplicação do ATIT, a delegação brasileira apresentou à delegação venezuelana um estudo comparativo das normas de pesos e dimensões em ambos os países. Ainda não há registro de acordos sobre a temática.

Revista Brasileira de Políticas Públicas e Internacionais, v.4, n.1, julho/2019, pp. 131-151. 
RIBEIRO, Hugo Alves Silva; PEIXOTO, Nathane Eva Santos; PINTO, Kleber Carlos Ribeiro. Harmonização de Normas para o Transporte Rodoviário Internacional de Cargas entre Países da América do Sul.

\subsection{Chile}

Em 1991, na III Reunião Bilateral Brasil-Chile, ambos os países concordaram em utilizar os métodos chilenos na determinação dos pesos e dimensões aceitáveis para os veículos rodoviários de carga. Em 2001, durante a VII Reunião Bilateral Brasil-Chile, a delegação chilena solicitou que o governo brasileiro aceitasse tolerância de $50 \mathrm{~cm}$ no comprimento máximo dos veículos.

Em 2003, na IX reunião bilateral entre as nações, a delegação brasileira decidiu não criar óbices nas operações de transporte dos veículos estrangeiros que ultrapassem as normas previstas na legislação brasileira, até que seja determinado acordo entre as partes.

Em 2007, na IV Reunião do conselho de segurança viária do Mercosul - Subgrupo de Trabalho Transportes, a delegação chilena alegou, durante as discussões das propostas apresentadas sobre pesos e dimensões, que o limite de carga por eixo simples de duas rodas em seu país era de 7 ton e não 6 ton conforme estava sendo a tendência de acordo entre as nações. Do mesmo modo, para eixo simples de quatro rodas era de 11 ton e não 10,5 ton, bem como que o eixo triplo de doze rodas era de 25 ton e não 25,5 ton. Ademais, o Chile alegava que a altura máxima de seus veículos era de 4,20 m, e não 4,30 m, e o comprimento máximo de um caminhão com um acoplamento era de 20,5 m e não 20 m. Ainda não há registro de acordos bilaterais entre Brasil e Chile sobre essa temática.

\subsection{Argentina}

Desde 1990 a delegação argentina aceitava, nos termos do Convênio do Transporte Internacional Terrestre do Cone Sul, a verificação técnica do material rodante e dos pesos e dimensões vigentes em seu país. Em 2006, por meio de acordo bilateral, ficou determinado que entre Brasil e Argentina haveria aceitação de veículos de carga com até 18,6 m de comprimento. Em 2007 a delegação brasileira solicitou que a altura máxima dos veículos pudesse ser de até 4,30 m, no entanto não houve consenso.

O governo argentino internalizou a Resolução GMC no 65/08 em 2010, por meio da Resolução da Secretaria de Transportes de n 197/2010, permitindo que fossem aplicadas as

Revista Brasileira de Políticas Públicas e Internacionais, v.4, n.1, julho/2019, pp. 131-151. 
RIBEIRO, Hugo Alves Silva; PEIXOTO, Nathane Eva Santos; PINTO, Kleber Carlos Ribeiro. Harmonização de Normas para o Transporte Rodoviário Internacional de Cargas entre Países da América do Sul.

regras acordadas em sua totalidade. No entanto, a sua operacionalização veio de forma paulatina.

Durante a Reunião Multilateral de aplicação do ATIT entre o Uruguai a Argentina e o Brasil ocorrida em 2013, acordou-se que esses Estados aplicariam a totalidade da Resolução GMC no $n^{\circ}$ /08 a partir de $1^{\circ}$ de julho daquele mesmo ano.

Desde 2011, quando ocorreu a XLIII Reunião do Subgrupo de trabalho $\mathrm{n}^{\mathrm{o}}$ 5, a delegação argentina vem apresentando propostas no sentido de uniformizar alguns temas polêmicos ainda indefinidos, tanto no campo do Mercosul quanto na temática bilateral com o Brasil, dos quais se destacam as tolerâncias máximas dos pesos e dimensões, e a diferenciação do comprimento máximo dos veículos dependendo do modelo do cavalo trator (veículos "cara chata" versus “bicudo"). Quanto à dimensão dos veículos tratores, foi proposto que o veículo "bicudo" pudesse ter até $20 \mathrm{~m}$ de comprimento, o que é maior que os 18,6 m acordado (Figura 7). Esse tema não foi acatado pelas delegações participantes, sendo retirado da pauta de discussão em 2014.

Figura 7: Proposta da delegação argentina rejeitada em 2014, que buscava elevar o comprimento máximo de veículos tratores do modelo "bicudo"

Veículo Trator "Cara Chata"

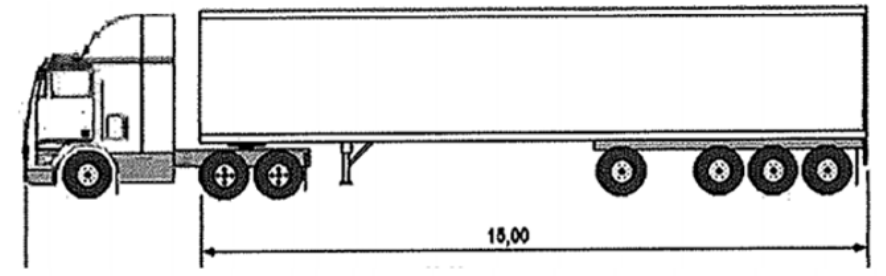

Veículo Trator "Bicudo"

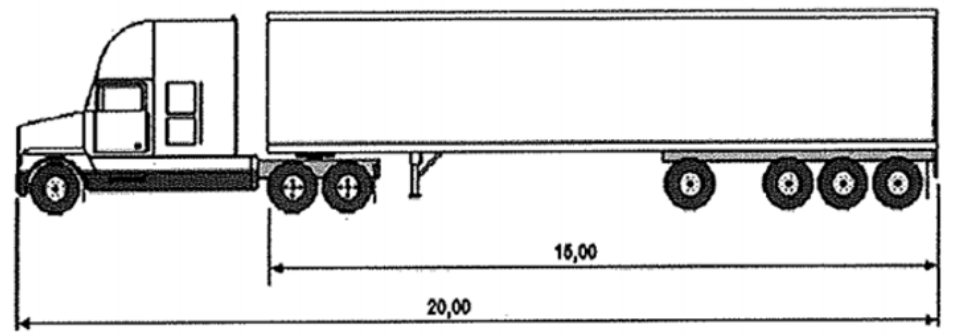

Fonte: Adaptado da ata da XLIII Reunião do Subgrupo de trabalho n ${ }^{\circ} 5$.

\section{Proposta de Harmonização}

Uma vez consolidados os normativos e as argumentações das delegações brasileira, paraguaia, uruguaia, boliviana, venezuelana, chilena e argenina, este trabalho permite propor

Revista Brasileira de Políticas Públicas e Internacionais, v.4, n.1, julho/2019, pp. 131-151. 
RIBEIRO, Hugo Alves Silva; PEIXOTO, Nathane Eva Santos; PINTO, Kleber Carlos Ribeiro. Harmonização de Normas para o Transporte Rodoviário Internacional de Cargas entre Países da América do Sul.

diretrizes para uma harmonização normativa na busca pelo consenso desses países. A intenção é que essa nova proposta seja apresentada pelo Brasil conjuntamente ao Mercosul e aos Estados Parte do ATIT visando a integração regional.

As diretrizes aqui colocadas consideraram as boas práticas das negociações internacionais e a técnica do direito comparado, bem como perseguiu os anseios do setor rodoviário de cargas na busca pela liberdade de uso das novas tecnologias que vêm sendo implantadas. Acerca disso destacam-se os caminhões cada vez maiores e mais seguros, e a utilização de pneus extralargos. Ressalta-se que essa abordagem converge harmoniosamente com aquilo já definido no Mercosul, com poucas adequações pontuais a fim de evitar os conflitos atualmente existentes. Diante do exposto, este estudo propõe as seguintes diretrizes:

- $\quad$ Não deve haver tolerância em balanças, uma vez que cada nação adota metodologias de medição e tecnologias distintas de balança.

- Quanto ao peso máximo por eixo, uma vez que não haveria tolerância nas balanças, sugere-se ampliar o limite de carga em 0,5 tonelada por eixo em comparação com a tabela do Mercosul, bem como ampliar o PBT máximo de 45 ton para 48,5 ton atendendo a parte dos anseios das delegações uruguaia, chilena e paraguaia.

- Deve-se permitir o uso de pneus extralargos em todos os países signatários do Mercosul e ATIT, tendo em vista que é uma tecnologia mais eficiente de pneumáticos para certas aplicações, e já utilizado internamente no Brasil, Uruguai, Argentina, Venezuela e Chile.

- O comprimento máximo do veículo deve ser independente das características do veículo trator ("bicudo" ou "cara chata"), conforme anseios de Brasil, Paraguai, Uruguai, Bolívia, Venezuela e Chile. Para o comprimento máximo, sugere-se como regra geral $20 \mathrm{~m}$ para caminhão trator com semirreboque e 20,5 m de caminhão com reboque, sem tolerâncias, buscando adequações com as regras de Argentina, Chile e Paraguai. As demais dimensões seriam análogas ao acordado pelo Mercosul.

- $\quad$ Em regra geral, deverá ser permitida altura máxima de 4,3 m conforme previsto no Mercosul. Excepcionalmente, algumas rotas com viadutos ou túneis podem ser restritas ao transporte desses veículos. Não deve haver tolerância de altura para o transporte convencional, apenas para cargas especiais devidamente autorizadas.

Revista Brasileira de Políticas Públicas e Internacionais, v.4, n.1, julho/2019, pp. 131-151. 
RIBEIRO, Hugo Alves Silva; PEIXOTO, Nathane Eva Santos; PINTO, Kleber Carlos Ribeiro. Harmonização de Normas para o Transporte Rodoviário Internacional de Cargas entre Países da América do Sul.

- $\quad$ Propõe-se que os demais pesos e dimensões não elencados nas diretrizes anteriores sejam mantidos nos moldes daquilo definido nas Resoluções do GMC.

Com isso, acredita-se no avanço das negociações na busca pela integração regional, uma vez que há subsídios para que cada país ceda a alguns de seus interesses para angariar o bem comum de todos. Ressalta-se que essas diretrizes consideraram os registros apontados nas atas de reunião e nos documentos técnicos selecionados pelo método anteriormente apresentado e, por essa razão, pressupõe-se que eventuais limitações de infraestrutura de cada país já tivessem sido tratadas durante as discussões. Assim, essas diretrizes foram obtidas por meio de evidências, e devidamente fundamentadas, o que potencializa o sucesso em negociações.

\section{Conclusão}

Este trabalho sistematizou técnicas de coleta de informações, as quais criam fundamentos para subsidiar negociações internacionais. Por meio do sistema TRI (ANTT, 2018) foi possível realizar o levantamento de 64 documentos, dentre normativos internos de cada nação, atas de reuniões bilaterais e multilaterais entre o Brasil e demais países.

A partir da análise dessas informações, foi possível utilizar as técnicas do direito comparado para identificar os anseios e limitações levantadas por cada delegação a fim de reduzir os riscos de futuras negociações infrutíferas entre os Estados Parte. A intenção é buscar meios para construir a integração regional da América do Sul em prol da harmonia entre as regulamentações dos pesos e dimensões dos veículos prestadores de serviço rodoviário internacional de cargas.

Diante da revisão desses documentos foram verificados os acordos que envolvem o Brasil e os seguintes países: Paraguai, Uruguai, Bolívia, Venezuela, Chile e Argentina. Como resultado, este trabalho propõe que as normas de pesos e dimensões do TRIC não contemplem quesitos de tolerância de balanças, mas em contrapartida, sejam ampliados os limites de carga em 0,5 toneladas por eixo em comparação com a tabela do Mercosul, bem como permita veículos com PBT máximo de até 48,5 ton. Ademais, a proposta recomenda autorizar o uso de pneus extralargos e aumentar o comprimento máximo do caminhão trator com semirreboque para $20 \mathrm{~m}$, e com reboque para 20,5 m. Quanto a altura máxima do veículo, propõe-se 4,3 m,

Revista Brasileira de Políticas Públicas e Internacionais, v.4, n.1, julho/2019, pp. 131-151. 
RIBEIRO, Hugo Alves Silva; PEIXOTO, Nathane Eva Santos; PINTO, Kleber Carlos Ribeiro. Harmonização de Normas para o Transporte Rodoviário Internacional de Cargas entre Países da América do Sul.

mantendo todos os outros regramentos nos moldes das Resoluções do GMC. Excepcionalmente, em rotas com limitações de infraestrutura, esses valores podem ser reduzidos. Isso, caso acatado, modificaria parte daquilo estabelecido na Resolução GMC n $^{\circ}$ $65 / 08$.

Ao final, essa propositura visa facilitar a movimentação de mercadorias por meio rodoviário entre os países da América do Sul, diminuindo barreiras logísticas e ampliando a eficiência do transporte. Como conclusão, o trabalho também auxilia no aperfeiçoamento da gestão pública internacional, uma vez que sistematiza meios para melhorar o planejamento e a estratégia em negociações.

\section{Referências}

ABTI - Associação Brasileira de Transportadores Internacionais (2016). Fluxos. Informações dos fluxos de veículos habilitados ao cruze internacional rodoviário de cargas (ingresso $e$ regresso). Disponível em: <http://www.abti.com.br/informacao/fluxos>. Acesso em 21 de abr. 2019.

Acuff, F. L. (2004). Como negociar qualquer coisa com qualquer pessoa em qualquer lugar do mundo. $2^{\mathrm{a}}$ Ed. São Paulo: Editora Senac São Paulo.

ANTT - Agência Nacional de Transportes Terrestres (2018). Sistema Transporte Rodoviário Internacional (TRI). Brasília-DF. Disponível em: <http://tri.antt.gov.br>. Acesso em 16 de fev. de 2018.

Cardoso, G. V. (2010). O direito comparado na jurisdição constitucional. Revista de Direito $G V$, São Paulo, 6 (2), 469 - 492.

CNI - Confederação Nacional das Indústrias (2015). Desafios para a integração logística na América do Sul. Armando Castelar. Brasília, 113 p.: II.

Comex Stat (2018). Sistema de Consulta e Extração de dados do Comercio Exterior. Disponível em: http://comexstat.mdic.gov.br/pt/home. Acesso em: 21 abr. 2019.

COSIPLAN - Consejo Suramericano de Infraecstrutura y Planeamiento (2017). Informe de Actividades 2017. Precidencia Pro Témpore - Argentina 2017-2018. Buenos Aires.

Frete Com Lucro (2019). Lei da balança, saiba seus direitos de forma prática. Disponível em: $<$ https://fretecomlucro.com.br/lei-da-balanca/>. Acesso em 02 de jun. 2019.

Revista Brasileira de Políticas Públicas e Internacionais, v.4, n.1, julho/2019, pp. 131-151. 
RIBEIRO, Hugo Alves Silva; PEIXOTO, Nathane Eva Santos; PINTO, Kleber Carlos Ribeiro. Harmonização de Normas para o Transporte Rodoviário Internacional de Cargas entre Países da América do Sul.

Gonçalves, R. (2016). Economia Política Internacional: edição atualizada - fundamentos Teóricos e as Relações Internacionais do Brasil. $2^{\mathrm{a}}$ ed. Rio de Janeiro. Elsevier Brasil

Granato, L., \& Batista, I. R. (2018). Mercosul à prova: estratégias e limites da integração regional periférica. Revista Brasileira de Políticas Públicas e Internacionais (RPPI), 3(1), 230253.

Huertas, D. M. (2013). Território e circulação: transporte rodoviário de carga no Brasil. Tese de Doutorado. Faculdade de Filosofia, Letras e Ciências Humanas, Universidade de São Paulo, São Paulo. doi:10.11606/T.8.2013.tde-04112013-130623

Jaeger, B. C. (2017) Investimentos chineses em infraestrutura na América do Sul: impactos sobre a Integração Regional. Revista Conjuntura Austral, Porto Alegre, 8 (39-40), p. 4-23.

Juárez, H. H., \& Conde, T. (2015). La importancia de las aduanas en el proceso de integración MERCOSUR. Revista de la Secretaría del Tribunal Permanente de Revisión, Asuncíon, 3 (6), p. $251-268$.

Lema, E. A. (2013). Effect of super single tires on Tanzania road network. Annual Road Convention, Dar es Salaam, Tanzania, 28 - 29 november.

Maia, E. G. R., \& Jacintho, J. M. M. (2018). A pesquisa e o direito comparado: um panorama evolutivo e os desafios enfrentados no Brasil. Revista de Pesquisa e Educação Jurídica, 4 (1), 54-70.

Mariano, A. M., \& Rocha, M. (2017) Revisão da literatura: apresentação de uma abordagem integradora. AEDEM International Conference. Reggio di Calabria (Italy).

Mitrany, D. (1933) The progress of international government. New Haven, CT: Yale University Press.

Nascimento, V. H. A., \& Muniz, T. L. (2012) A Unificação do Direito Privado no Mercosul segundo o Direito Comparado Funcional. Scientia Iuris, 16 (2), 143-174.

Pinto, M. S. (2004) A Área de Livre Comércio das Américas e os interesses da União Europeia na América Latina. Tese de Doutorado apresentada na Escola de Economia e Gestão da Universidade do Minho, Portugal.

Putnam, R. (1993). Diplomacy and domestic politics - The logic of Two Level Games. In: Putnam, R., Jacobson, H., \& Evans, P. Double-Edge Diplomacy - International bargaining and domestic politics. University of California Press, 1993.

Revista Brasileira de Políticas Públicas e Internacionais, v.4, n.1, julho/2019, pp. 131-151. 
RIBEIRO, Hugo Alves Silva; PEIXOTO, Nathane Eva Santos; PINTO, Kleber Carlos Ribeiro. Harmonização de Normas para o Transporte Rodoviário Internacional de Cargas entre Países da América do Sul.

Ribeiro, H. A. S. (2017). Cotas de transporte rodoviário de cargas entre o Brasil e o Peru: razões para eliminá-las. Revista Cenário do Transporte. Associação Brasileira de Transportadores Internacionais - ABTI. Ano XI, Ed. 46, p. 11-13. Disponível em: <http://www.abti.com.br/images/cenario-do-transporte/pdfs/46.pdf>. Acesso em 02 de jun. 2019.

Rotondo, S. (2018). O transporte rodoviário internacional de cargas e o processo de integração sul-americano. In. Anuário NTC\&Logística 2017 - 2018, Edição Técnica. Especial da Revista Brasil Transportes, p. $132 \quad-\quad 145 . \quad$ Disponível em: <https://www.portalntc.org.br/images/jce/arq_down/anuario_NTC_2017-2018.pdf>. Acesso em 02 de jun. 2019.

Santos, T (2017). Integração regional como Política Pública para a América do Sul: uma análise à luz da Faixa de Fronteira brasileira. Monções: Revista de Relações Internacionais da UFGD, Dourados, 6 (12), 177 - 198.

Veiga, J. P. C. (2002). Regime automotivo brasileiro: negociações internacionais. São Paulo em Perspectiva. 16 (2), 76 - 81.

Revista Brasileira de Políticas Públicas e Internacionais, v.4, n.1, julho/2019, pp. 131-151. 